\title{
EVALUATION OF THE ATTITUDES AND EXPERIENCES OF THE FAMILY PHYSICIANS AND SPECIALISTS RELATING TO PROVIDED TREATMENTS IN TERMS OF RATIONAL USE OF MEDICINE
}

\author{
Akici Ahmet $^{1 *}$, Kilboz Mehmet Murat ${ }^{1}$, Tamirci Mevhibe ${ }^{1}$, Aydin Volkan', Mollahaliloglu Salih ${ }^{2}$, \\ Ozgulcu Senay ${ }^{3}$, Alkan $\mathrm{Ali}^{4}$ \\ ${ }^{1}$ Department of Medical Pharmacology, Marmara University Faculty of Medicine, Istanbul, Turkey \\ ${ }^{2}$ Department of Public Health, Yildirim Beyazit University Faculty of Medicine, Ankara, Turkey \\ ${ }^{3}$ Department of Zoonotic and Vector Borne Diseases, Turkish Public Health Institution, Ministry of Health, Ankara, Turkey \\ ${ }^{4}$ Department of Rational Drug Use, Drug Supply Management, Turkish Medicines and Medical Devices Agency, Ministry of Health, Ankara, Turkey
}

\section{ABSTRACT}

Introduction: Physicians' perspectives are essential for rational use of medicine (RUM) activities. This study aimed at evaluation of physicians' attitudes and experiences about therapeutical management process in terms of RUM in primary and secondary care.

Methods: A survey was applied to 1062 family physicians (FP) and 562 specialist physicians (SP) in Turkey. The questionnaire consisted of items assessing physicians' RUM approaches, stratified by their demographic and occupational characteristics.

Results: A total of $55.4 \%$ of FPs and $32.1 \%$ of SPs declared that they prescribed to " $>80 \%$ of their patients". The attitude of "no prescribing without physical examination" was more in females, in seniors, and in those with longer professional experiences in SP group $(\mathrm{p}<0.05)$, where no difference was found among FPs. More markedly in FPs, women provided more information than men about their patients' diseases and pharmacological/non-pharmacological treatments. Most commonly demanded drugs by patients were "analgesics/antirheumatics", "cold-medications", and "antibiotics".

Conclusion: Physicians' statements showed that patients had an underestimated tendency to demand specific drug prescriptions and physicians met such demands more than expected. Moreover, female physicians are more likely to inform their patients about pharmacotherapy details in both groups. These findings may be considered as beneficial for RUM dissemination activities.

Key words: physicians, rational drug use, primary health care, hospitals, prescribing

Akici A, Kilboz MM, Tamirci M, Aydin V, Mollahaliloglu S, Ozgulcu S, Alkan A, Evaluation of the attitudes and experiences of the family physicians and specialists relating to provided treatments in terms of rational use of medicine, Journal of Drug Delivery and Therapeutics. 2017; 7(2):18-28. DOI: http://dx.doi.org/10.22270/iddt.v7i2.1383

\section{INTRODUCTION}

Recently, rational use of medicine (RUM) gains a vital importance regarding sustainable delivery of highquality healthcare. In case of failure to comply with the principles of the RUM, healthcare systems could be faced with significant risk, especially in terms of drugrelated problems and drug wastage. The role of the physicians in dealing with such threats is undisputedly important. World Health Organization (WHO) defined
RUM as "patients receive medications appropriate to their clinical needs, in doses that meet their own individual requirements, for an adequate period of time, and at the lowest cost to them and their community". 1 As implied by this description, abiding by basic principles of treatment process is fundamental to reaching success in a specific area like drug utilization. It is obvious that adoption of this approach requires a professional, physician-centered understanding. ${ }^{1-3}$ 
The issues emerging in case of failure to comply with the requirements of RUM is known as irrational use of medicine (IUM), which is listed among the important health problems strongly focused on by Turkey and many other countries. Review of the attitudes and experiences of the physicians who play a key role in managing treatment, and consequent implementation of the necessary precautions may contribute to solve these problems. In this context, physicians usually failed to show expected level of performance to carry out RUM, as indicated in the literature. ${ }^{4-12}$ In fact, their performances might be influenced by certain factors such as the place where healthcare is provided, their occupational and demographic features. Recently, infrastructure of the healthcare services began to undergo fundamental changes in Turkey, where, for instance, family health centers (FHC) has replaced health centers and governmental state hospitals $(\mathrm{SH})$ has experienced several changes and transformations. ${ }^{13,14}$ Continuous monitoring, evaluation, and comparison of the dynamic process of drug utilization increases the success of the dissemination of the RUM. Thus, WHO and other partners are striving to develop various criteria, approaches, and opinions that may contribute to research methodology allowing for spread of RUM. ${ }^{15,1,16,17}$

This study aimed at the evaluation of the prescriptionrelated attitudes and experiences of the family physicians (FP) and specialist physicians (SP) in terms of RUM and at the comparison of these two physician groups based on their general and professional characteristics that might influence their approach to RUM.

\section{METHOD}

In this descriptive study, a survey in May 2010 was applied to randomly chosen FPs working in FHCs in Turkey`s 12 provinces and to SPs working in SHs in these provinces. Upon the application of this face-toface interview survey to 1624 physicians in total, the knowledge, attitude, and experiences of the FPs and SPs regarding RUM were analyzed.

The FP survey was planned to cover all the FPs working in FHCs in these provinces. However, some physicians who were inaccessible during the survey period due to some reasons like day-off or temporary assignment to other provinces were excluded from the survey, and the questionnaire was administrated to a total of 1062 FPs (response rate: 97.2\%). With the support of the Provincial Health Directorates of these provinces, the number of the SPs working in SH of these provinces were determined and then the survey was applied to a total of 562 SPs out of the selected sample (response rate: $74.8 \%$ ). In the survey applied to SPs, the data were collected without any restrictions regarding the expertise of physicians.

The survey included physicians' descriptive characteristics, drug utilization habits, knowledge, attitude, and experiences of both physicians and their patients regarding RUM. Answers of the FPs and SPs were compared as each group within themselves based on their demographic and occupational characteristics.
Because of the extensive coverage of the collected information, research data will be discussed in different articles. This article only focuses on research data about physicians' experiences and attitudes regarding their approaches to the patients.

In order to implement the survey in 12 provinces, officially a permission received from Turkish Ministry of Health $(\mathrm{MoH})$. After a training for interviewers including information about the aim of the survey, application format, and other related procedures, data collection was begun. Demographic characteristics of age and working duration were presented in groups to make these data easy to understand. Accordingly, the age group of the physicians was named as "younger physicians" for those being $\leq 35$ year-old, "middle-aged physicians" for those 36-45 year-old and "45+ physicians" for those $>45$ year-old. Physicians were divided into two groups based on length of professional experiences. Accordingly, physicians working for " $\leq 10$ years" and ">10 years" were classified as "junior" and "senior", respectively. SPs were categorized according to their duration of expertise.

For analyzing the data, Microsoft-Office-Excel and SPSS-11.5 statistics pack software were used. Chisquare test was used to analyze within-group relationships of the FP and SPs' data. $\mathrm{P}<0.05$ was accepted as the level of statistical significance.

\section{RESULTS}

A total of 1624 physicians were surveyed, among which $1062(65.4 \%)$ were FPs and the remaining 562 (34.6\%) were SPs. In both FP and SP groups, men were in the majority (68.9\% and $74.2 \%$, respectively) and mean age of the participants were $39.1 \pm 6.4$ and $41.3 \pm 8.5$, respectively. About half of FPs (50.8\%) and $39.1 \%$ of SPs reported the duration from their graduation till survey as "11-20 years". It was also detected that 55.5\% of the SP completed their residency in a university hospital.

Based on the participants' statements, an average of 52 and 48 patients per day were found to apply to an FP and an SP, respectively. Most FPs wrote a prescription in more than $40 \%$ of their patients, of which $55.4 \%$ "prescribed in $81-100 \%$ of the patients" and $43.2 \%$ "prescribed in $41-80 \%$ of the patients". SPs replied same question as "prescribing $41-80 \%(56.3 \%)$ of the patients" and "prescribing $81-100 \%(32.1 \%)$ of the patients". "Prescribing $40 \%$ and less of the patients" answer were $1.4 \%$ and $11.6 \%$ in FPs and SPs, respectively.

The percentage of physicians who declared that they examined $3 / 4$ of patients applied them were $40.1 \%$ in FPs and $84.9 \%$ in SPs. Physicians stating to prescribe in more than three-fourths of patients upon physical examination (PE) were $70.0 \%$ in FPs and $64.0 \%$ in SPs.

Based on their experiences, the average number of drug items declared to be written by FPs and SPs were $3.27 \pm 0.6$ and $3.07 \pm 0.8$ per prescription, respectively. When the details of the number of drugs per prescription (NDPP) were examined, in both groups most commonly "three drug items" (64.4\% and 53.2\%, respectively) 
were prescribed, followed by "four drug items" (30.7\% and $25.9 \%$, respectively) and "two drug items" (4.7\% and $19.4 \%$, respectively). There was no FP who declared to write one drug item per prescription, which was detected to be written by five $(0.9 \%)$ physicians in SP group.

Only few physicians, $1.5 \%$ in the FP group and $0.7 \%$ in the SP group, stated that "they wrote a prescription to their patients just based on their complaints without performing PE". Participants exhibiting this attitude "sometimes" was $54.5 \%$ in FPs and $34.6 \%$ in SPs. Forty-four percent of FPs and $64.7 \%$ of SPs stated that "they did not prescribe drugs to their patients without PE". The association between characteristics of the physicians and "prescribing medicines just based on patient complaints without PE" were also compared.
While there was no significant correlation in FPs, a significant correlation was found between the answers of SP group and some of their characteristics. Majority of men $(60.6 \%)$ and women $(76.4 \%)$ in SP group "did not prescribe unless they performed a PE". SPs having this attitude "sometimes" were $30.9 \%$ among juniors and $42.6 \%$ among seniors. The percentage of SPs who stated that "they did not write any prescription without PE" were $68.1 \%$ among juniors and $57.4 \%$ in seniors. There was statistically significant correlation between the gender, age, and working duration as SP and "prescribing just based on complaints without PE" $(\mathrm{p}<0.05)$. Accordingly, those "writing a prescription based on just complaints without PE" were tended to be rather men, SPs above the age of 45 and junior SPs (Table 1).

Table 1: Comparison of status of writing a prescription just upon the complaint without physical examination by general and professional characteristics of physicians.

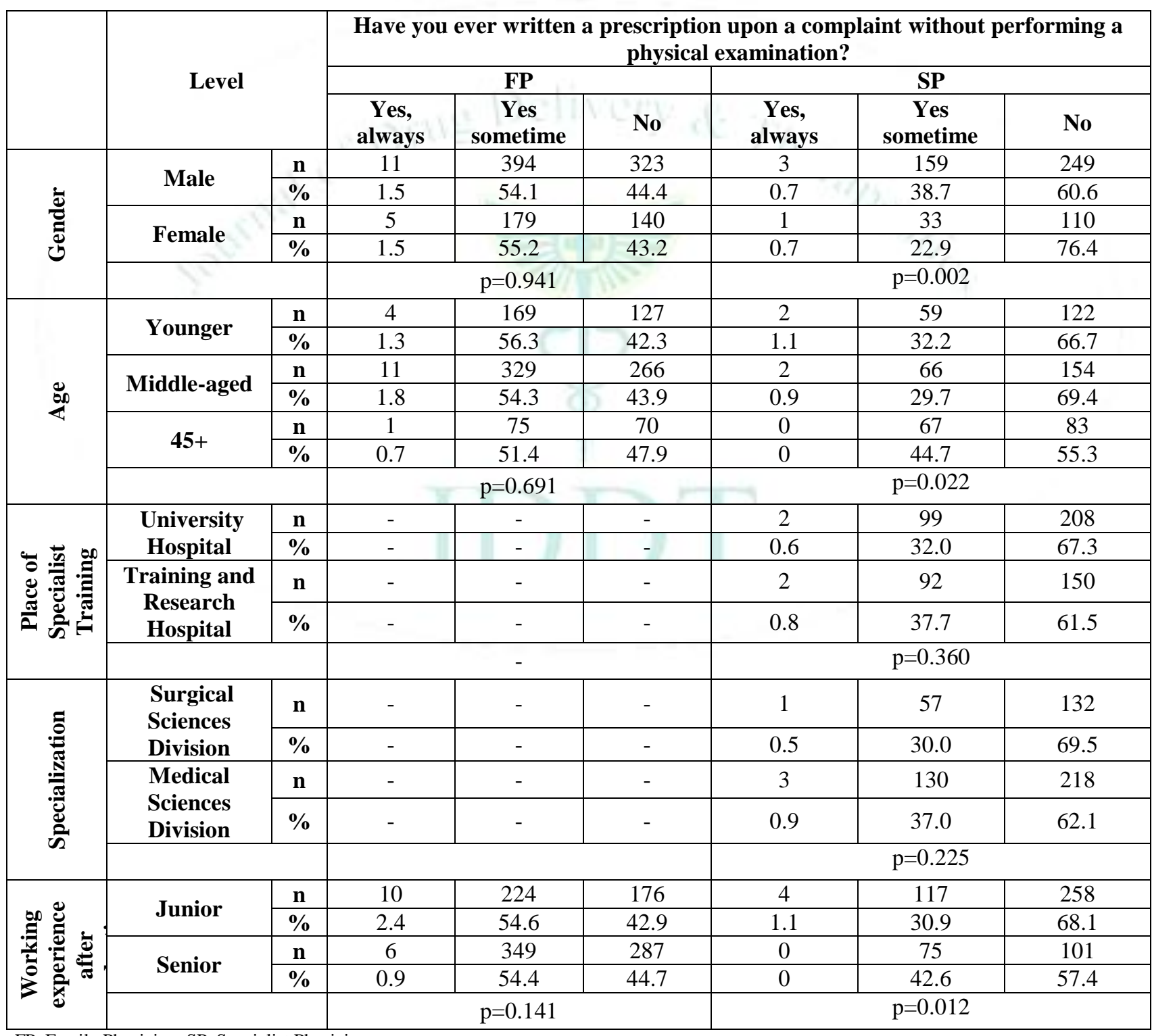

FP, Family Physician; SP, Specialist Physician

More than three-fourths of physicians $(77.9 \%$ of FPs, $82.6 \%$ of SPs) mentioned that they "always" provided information to the patients about their illness. Only $0.5 \%$ of FPs and $2 \%$ of SPs declared that "they provided no information or only if the patients would have asked". Majority of both FPs and SPs $(64.9 \%$ and $68.1 \%$, respectively) declared that they "always" provided information about the usage of prescribed drugs. 
Physicians having this attitude "sometimes" were $32.8 \%$ in FP and $26.5 \%$ in SP group. Only $2.1 \%$ of the FPs and $4.5 \%$ of the SPs stated that they provided this information "upon patient request". Around half of FPs
$(50.4 \%)$ and SPs $(56.1 \%)$ declared that they advised non-pharmacological therapy only for certain diseases. Moreover, \%2 of FPs and $7.1 \%$ of SPs did not even offer non-pharmacological therapy (Table 2).

Table 2: Assessment of whether physicians provide the patients with information about their disease, prescribed drugs, and nonpharmacological therapy [the comparisons were made over the subgroups of gender, age, duration of working, and "duration of working as SP". Statistically significant differences in these comparisons are indicated in the table by " $a$ " (gender), " $b$ " (age), " $c$ " (duration of working), and " $d$ " (duration of working as SP].

\begin{tabular}{|c|c|c|c|c|c|c|c|c|c|c|c|}
\hline \multirow{2}{*}{\multicolumn{2}{|c|}{ Described patient information }} & \multicolumn{2}{|c|}{$\begin{array}{c}\text { Yes, } \\
\text { always }\end{array}$} & \multicolumn{2}{|c|}{$\begin{array}{c}\text { Yes, } \\
\text { sometimes }\end{array}$} & \multicolumn{2}{|c|}{$\begin{array}{l}\text { When asked } \\
\text { by patients }\end{array}$} & \multicolumn{2}{|c|}{$\begin{array}{l}\text { Only for some } \\
\text { diseases }\end{array}$} & \multicolumn{2}{|c|}{ No } \\
\hline & & $\%$ & $\mathrm{n}$ & $\%$ & $\mathrm{n}$ & $\%$ & $\mathrm{n}$ & $\%$ & $\mathrm{n}$ & $\%$ & $\mathrm{n}$ \\
\hline \multirow{2}{*}{$\begin{array}{l}\text { Do you give patients } \\
\text { information about the } \\
\text { disease? }\end{array}$} & FP $a$ & 77.9 & 820 & 21.6 & 227 & 0.3 & 3 & - & - & 0.2 & 3 \\
\hline & SP & 82.6 & 456 & 15.4 & 85 & 1.6 & 9 & - & - & 0.4 & 2 \\
\hline \multirow{2}{*}{$\begin{array}{l}\text { Do you explain } \\
\text { patient how to use } \\
\text { the medicine you } \\
\text { prescribe? }\end{array}$} & $\mathrm{FP} a, c$ & 64.9 & 680 & 32.8 & 344 & 2.1 & 22 & - & - & 0.2 & 2 \\
\hline & $\mathrm{SP} \boldsymbol{a}, \boldsymbol{b}, \boldsymbol{d}$ & 68.1 & 377 & 26.5 & 147 & 4.5 & 25 & - & - & 0.9 & 5 \\
\hline \multirow{2}{*}{$\begin{array}{l}\text { Do you recommend } \\
\text { non-pharmacological } \\
\text { therapy? }\end{array}$} & $\mathrm{FP} a$ & 25.3 & 265 & 22.3 & 233 & - & - & 50.4 & 528 & 2.0 & 21 \\
\hline & SP & 16.7 & 93 & 20.1 & 111 & - & - & 56.1 & 310 & 7.1 & 39 \\
\hline
\end{tabular}

FP, Family Physician; SP, Specialist Physician

The answers of FPs and SPs regarding "providing information to their patients about their diseases" were compared by their "gender, age, and working duration". No significant correlation was found among any of the compared strata of SPs $(p>0.05)$. In FP group, a significant difference was merely detected in gender stratum $(\mathrm{p}<0.05)$, (Table 2). Accordingly, the percentage of females who declared to "provide information to their patients about their diseases" was higher (84.8\%) than that of their male counterparts (74.9) in FP group (Figure).

The answers of the FPs regarding "providing information to their patients about use of the drugs written in the prescription" were compared by their "gender, age, and working duration". It was identified that there were statistically significant differences within the gender and working duration strata of the FPs $(p<0.05)$, (Table 2). These comparisons showed that the percentage of female and junior physicians who stated to "give this information to their patients" were higher ( $71.3 \%$ and $68.9 \%$, respectively) than that of male and senior physicians $(62.1 \%$ and $59.0 \%$, respectively) in FP group (Figure). The comparisons within the "gender, age, and working duration" strata of the SP group concerning "providing information to their patients about use of the drugs written in the prescription" demonstrated statistically significant differences $(\mathrm{p}<0.05)$, (Table 2$)$. The analysis revealed significantly higher percentage of female, younger and junior physicians who declared to show this attitude always (76.4\%, $74.7 \%$, and $72.1 \%$, respectively), as compared to that of male $(65.1 \%)$, middle-aged $(68.0 \%)$ and $45+$ $(60.0 \%)$, and senior SPs $(61.0 \%)$, respectively (Figure).

The responses of the FP and SP groups about "recommendation of non-pharmacological therapy to their patients" were compared by their "gender, age, and working duration". While no significant difference was detected within subgroups of the SPs $(p>0.05)$, gender stratum showed a significant difference in the FP group $(\mathrm{p}<0.05)$, (Table 2$)$. The percentage of female physicians who declared to "always recommend nonpharmacological therapy to their patients" was higher $(31.4 \%)$ than that of male physicians $(22.6 \%)$ in FP group (Figure).

Considering the information provided by FPs and SPs to patients about their diseases, the type of information given by physicians most frequently were about "the treatment" (94.4\% and $92.7 \%$, respectively). In both FP and SP groups, this was followed by "the reason" (90.2\% and $90.0 \%$, respectively), "the name" $(89.5 \%$ and $88.5 \%$, respectively), "the complications" (80.6\% and $80.5 \%$, respectively), "the consequences" (78.2\% and $83.2 \%$, respectively), and "the pathophysiology" $(35.1 \%$ and $41.3 \%$, respectively) of the disease. 


\section{Giving Information to the Patients}

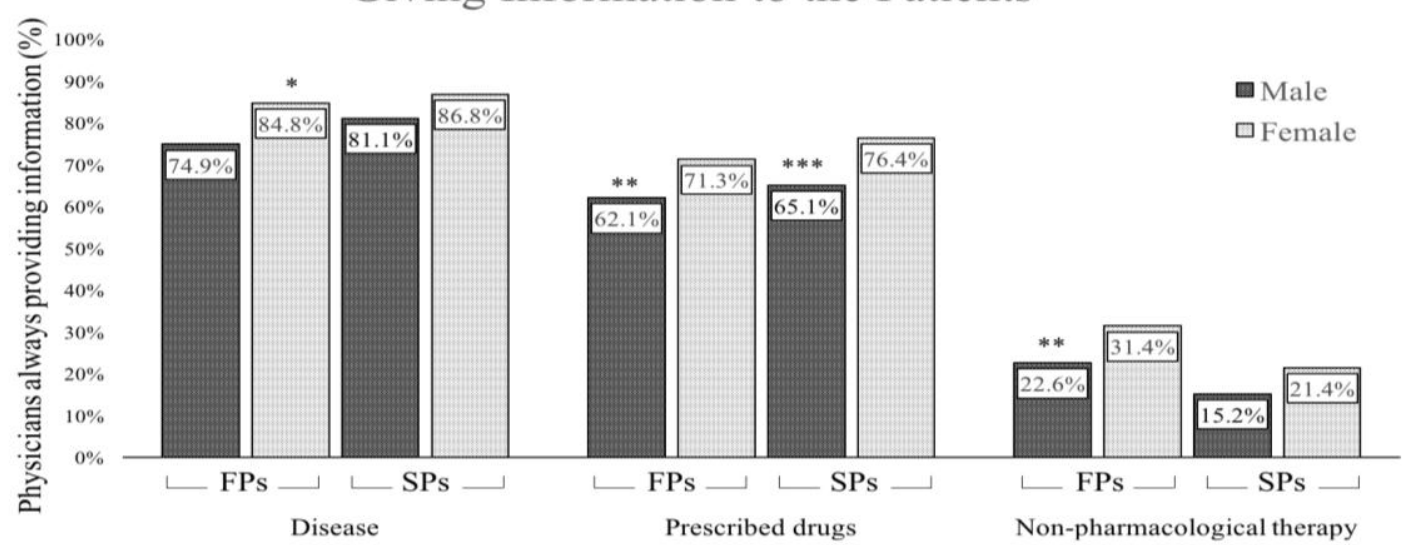

Figure 1: Gender distribution of information about the disease, prescribed drugs, and non-pharmacological therapy "always provided" by the physicians (*; $p<0.005$ compared to male FPs, **; $p<0.05$ compared to male FPs, ***; $p<0.05$ compared to male $S P s)$. FP, Family Physician; SP, Specialist Physician

When the types of information about drugs that was "always" provided by FPs and SPs to their patients was considered, most frequently given information in both groups was about "dosage" $(59.1 \%$ and $66.1 \%$, respectively); followed by "duration of treatment"
(56.7\% and $64.6 \%$, respectively), and "administration way" (56.5\% and $62.3 \%$, respectively). On the other hand, $36.1 \%$ of FPs and $40.9 \%$ SPs declared that they "rarely or never" tell their patients "the name of the drug" (Table 3).

Table 3: Distribution of drug information that physicians declared to provide their patients.

\begin{tabular}{|c|c|c|c|c|c|c|c|c|c|}
\hline \multirow{2}{*}{\multicolumn{2}{|c|}{ Drug information }} & \multicolumn{4}{|c|}{ FP } & \multicolumn{4}{|c|}{ SP } \\
\hline & & Always & Often & Rarely & Never & Always & Often & Rarely & Never \\
\hline \multirow{2}{*}{ Name } & $\mathbf{n}$ & 233 & 420 & 326 & 43 & 150 & 176 & 164 & 61 \\
\hline & $\%$ & 22.8 & 41.1 & 31.9 & 4.2 & 27.2 & 31.9 & 29.8 & 11.1 \\
\hline \multirow{2}{*}{ Administration way } & $\mathbf{n}$ & 590 & 426 & 26 & 2 & 343 & 177 & 25 & 6 \\
\hline & $\%$ & 56.5 & 40.8 & 2.5 & 0.2 & 62.3 & 32.1 & 4.5 & 1.1 \\
\hline \multirow{2}{*}{ Dosage } & $\mathbf{n}$ & 616 & 384 & 38 & 4 & 365 & 157 & 25 & 5 \\
\hline & $\%$ & 59.1 & 36.9 & 3.6 & 0.4 & 66.1 & 28.5 & 4.5 & 0.9 \\
\hline \multirow{2}{*}{ Duration of treatment } & $\mathbf{n}$ & 589 & 406 & 41 & 4 & 356 & 173 & 16 & 6 \\
\hline & $\%$ & 56.7 & 39.0 & 3.9 & 0.4 & 64.6 & 31.4 & 2.9 & 1.1 \\
\hline \multirow{2}{*}{ Mechanism of action } & $\mathbf{n}$ & 84 & 178 & 636 & 119 & 59 & 107 & 283 & 100 \\
\hline & $\%$ & 8.3 & 17.5 & 62.5 & 11.7 & 10.7 & 19.5 & 51.5 & 18.3 \\
\hline \multirow{2}{*}{ Side effects } & $\mathbf{n}$ & 151 & 531 & 327 & 20 & 122 & 277 & 125 & 25 \\
\hline & $\%$ & 14.7 & 51.6 & 31.8 & 1.9 & 22.3 & 50.5 & 22.7 & 4.5 \\
\hline \multirow{2}{*}{ Cost } & $\mathbf{n}$ & 37 & 77 & 537 & 367 & 29 & 49 & 209 & 262 \\
\hline & $\%$ & 3.6 & 7.6 & 52.7 & 36.1 & 5.3 & 8.9 & 38.1 & 47.7 \\
\hline \multirow{2}{*}{ Interactions } & $\mathbf{n}$ & 117 & 521 & 358 & 26 & 74 & 250 & 187 & 38 \\
\hline & $\%$ & 11.5 & 51.0 & 35.0 & 2.5 & 13.5 & 45.5 & 34.1 & 6.9 \\
\hline \multirow{2}{*}{ Avoided activities } & $\mathbf{n}$ & 166 & 461 & 356 & 37 & 108 & 242 & 161 & 39 \\
\hline & $\%$ & 16.3 & 45.2 & 34.9 & 3.6 & 19.6 & 44.0 & 29.3 & 7.1 \\
\hline \multirow{2}{*}{ End of treatment } & $\mathbf{n}$ & 392 & 551 & 76 & 10 & 268 & 237 & 33 & 13 \\
\hline & $\%$ & 38.1 & 53.5 & 7.4 & 1.0 & 48.6 & 43.0 & 6.0 & 2.4 \\
\hline
\end{tabular}

FP, Family Physician; SP, Specialist Physician

Physicians declared that their patients requested prescriptions about certain drug groups "very frequently", "frequently", or "mid-frequently". The drugs requested to be prescribed "very frequently" were "analgesic and antirheumatic drugs" (76\% in FPs and $50.5 \%$ in SPs) and "common cold drugs" (49.0\% in FPs and $28.5 \%$ in SPs). About one-fourth of FPs declared that patients applied them for the demand of antibiotic prescription "very frequently", "frequently", and "midfrequently" (26.2\%, 26.9\%, and $26.1 \%$, respectively). This statement about antibiotic prescriptions was identified in $24.2 \%, 29.2 \%$ and $18.9 \%$ of SP group, respectively (Table 4 ). 
Table 4: Frequency of drug demands to be prescribed by the physicians.

\begin{tabular}{|c|c|c|c|c|c|c|c|c|c|c|c|}
\hline \multirow{2}{*}{\multicolumn{2}{|c|}{ Queried drugs }} & \multicolumn{5}{|c|}{ FP } & \multicolumn{5}{|c|}{ SP } \\
\hline & & \multirow{2}{*}{\begin{tabular}{c|}
$\begin{array}{c}\text { Very } \\
\text { frequently }\end{array}$ \\
790
\end{tabular}} & \multirow{2}{*}{$\begin{array}{c}\text { Frequently } \\
180 \\
\end{array}$} & \multirow{2}{*}{\begin{tabular}{|c|}
$\begin{array}{c}\text { Mid- } \\
\text { frequently }\end{array}$ \\
53 \\
\end{tabular}} & \multirow{2}{*}{\begin{tabular}{c|} 
Rarely \\
11
\end{tabular}} & \multirow{2}{*}{\begin{tabular}{|c|} 
Never \\
5
\end{tabular}} & \multirow{2}{*}{\begin{tabular}{|c|}
$\begin{array}{c}\text { Very } \\
\text { frequently }\end{array}$ \\
274 \\
\end{tabular}} & \multirow{2}{*}{\begin{tabular}{|c|} 
Frequently \\
151 \\
\end{tabular}} & \multirow{2}{*}{\begin{tabular}{|c|}
$\begin{array}{c}\text { Mid- } \\
\text { frequently }\end{array}$ \\
59 \\
\end{tabular}} & \multirow{2}{*}{\begin{tabular}{|c|} 
Rarely \\
23
\end{tabular}} & \multirow{2}{*}{$\frac{\text { Never }}{35}$} \\
\hline Analgesic/ & $\mathbf{n}$ & & & & & & & & & & \\
\hline antirheumatic drugs & $\%$ & 76.0 & 17.3 & 5.1 & 1.1 & 0.5 & 50.5 & 27.9 & 10.9 & 4.2 & 6.5 \\
\hline \multirow{2}{*}{ Cold drugs } & $\mathbf{n}$ & 509 & 341 & 143 & 34 & 12 & 151 & 155 & 89 & 77 & 58 \\
\hline & $\%$ & 49.0 & 32.8 & 13.8 & 3.2 & 1.2 & 28.5 & 29.3 & 16.8 & 14.5 & 10.9 \\
\hline \multirow{2}{*}{ Antibiotics } & $\mathbf{n}$ & 275 & 281 & 273 & 186 & 31 & 131 & 158 & 102 & 113 & 37 \\
\hline & $\%$ & 26.2 & 26.9 & 26.1 & 17.8 & 3.0 & 24.2 & 29.2 & 18.9 & 20.9 & 6.8 \\
\hline \multirow{2}{*}{$\begin{array}{l}\text { Gastrointestinal } \\
\text { system drugs }\end{array}$} & $\mathbf{n}$ & 228 & 413 & 257 & 97 & 37 & 100 & 150 & 111 & 92 & 77 \\
\hline & $\%$ & 22.1 & 40.0 & 24.9 & 9.4 & 3.6 & 18.9 & 28.3 & 20.9 & 17.4 & 14.5 \\
\hline \multirow{2}{*}{ Antihypertensives } & $\mathbf{n}$ & 168 & 222 & 178 & 300 & 153 & 68 & 117 & 121 & 115 & 110 \\
\hline & $\%$ & 16.5 & 21.7 & 17.4 & 29.4 & 15.0 & 12.8 & 22.0 & 22.8 & 21.7 & 20.7 \\
\hline \multirow{2}{*}{$\begin{array}{l}\text { Antihyper- } \\
\text { lipidemics }\end{array}$} & $\mathbf{n}$ & 60 & 137 & 212 & 392 & 215 & 31 & 75 & 100 & 163 & 162 \\
\hline & $\%$ & 5.9 & 13.5 & 20.9 & 38.5 & 21.2 & 5.8 & 14.2 & 18.8 & 30.7 & 30.5 \\
\hline \multirow{2}{*}{$\begin{array}{l}\text { Other } \\
\text { cardiovascular } \\
\text { drugs }\end{array}$} & $\mathbf{n}$ & 88 & 149 & 180 & 313 & 281 & 28 & 69 & 98 & 169 & 167 \\
\hline & $\%$ & 8.7 & 14.7 & 17.8 & 31.0 & 27.8 & 5.2 & 13.0 & 18.5 & 31.8 & 31.5 \\
\hline \multirow{2}{*}{$\begin{array}{l}\text { Asthma / COPD } \\
\text { medications }\end{array}$} & $\mathbf{n}$ & 43 & 120 & 277 & 383 & 189 & 34 & 55 & 96 & 170 & 174 \\
\hline & $\%$ & 4.2 & 11.9 & 27.4 & 37.8 & 18.7 & 6.4 & 10.4 & 18.1 & 32.2 & 32.9 \\
\hline \multirow{2}{*}{$\begin{array}{l}\text { Vitamin / mineral } \\
\text { preparations }\end{array}$} & $\mathbf{n}$ & 130 & 194 & 293 & 334 & 67 & 60 & 86 & 103 & 161 & 120 \\
\hline & $\%$ & 12.8 & 19.1 & 28.8 & 32.8 & 6.5 & 11.3 & 16.2 & 19.5 & 30.4 & 22.6 \\
\hline \multirow{2}{*}{ Iron supplements } & $\mathbf{n}$ & 37 & 127 & 363 & 389 & 96 & 26 & 49 & 100 & 204 & 150 \\
\hline & $\%$ & 3.7 & 12.5 & 35.9 & 38.4 & 9.5 & 4.9 & 9.3 & 18.8 & 38.6 & 28.4 \\
\hline
\end{tabular}

FP, Family Physician; SP, Specialist Physician; COPD, Chronic Obstructive Pulmonary Medicine

Mean duration of interviews with patients were declared to be " $\leq 5$ minutes" in $30.6 \%$ of FPs and $50.3 \%$ of SPs, "6-10 minutes" in $52.7 \%$ of FPs and $38.0 \%$ of SPs, " $11-$ 15 minutes" in $13.7 \%$ of FPs and $9.5 \%$ of SPs, and " $>15$ minutes" in $3.0 \%$ of FPs and $2.2 \%$ of SPs. While the average duration for interview allocated by FPs to their patients was estimated to be 8 minutes and 58 seconds ( $\pm 4 \mathrm{~min}$.), this was found to be 7 minutes and 33 seconds ( \pm 4 min.) in SP group. FPs and SPs thought this duration as "insufficient" $(26.3 \%$ and $35.9 \%$, respectively) or "partially sufficient" (54.0\% and $48.6 \%$, respectively). On the other hand, substantial number of FPs and SPs thought this duration to be at least ">15 minutes" (32.8\% and $28.1 \%$, respectively).

The relation between physicians' daily patient volume and the adequate time they allocated for drug selection was questioned. Nearly all physicians $(98.2 \%$ of FPs and $97.2 \%$ of SPs) declared that they could have allowed adequate time for drug selection (i.e. identifying effective, safe, suitable, low-cost drugs) if the number of their patients had been $<20$ per day. The physicians who pointed out this number as "20-40 patients per day" (92.8\% of FPs and $89.5 \%$ of SPs) also declared that they could allow adequate time for drug selection. Nevertheless, when it exceeded 40 patients per day, these numbers were shown to markedly decrease in both groups. When their daily volume was 41-60 patients per day, $50 \%$ of the FPs and $45.2 \%$ of the SPs declared that they were able to devote adequate time for drug selection. In case that it was $>60$ patients per day, more than $80 \%$ of both FPs and SPs stated that they could not spare adequate time for drug selection.
Physicians' habits of "making their patients to repeat the explanations" after they gave information about drug usage to make sure that this information was properly understood were analyzed. Physicians declaring to practice this habit "always" constituted $10.4 \%$ of FPs and $11.3 \%$ of SPs. Majority of physicians had the habit "sometimes" (73.7\% of FPs and $68.8 \%$ of SPs), and those practicing this habit "never" were $15.9 \%$ in FP group and $19.9 \%$ in SP group.

\section{DISCUSSION}

There were 64,756 general practitioners and SPs in total, working in $\mathrm{MoH}$ in 2010 in Turkey. ${ }^{18}$ Considering that, a high level of participation of $2.5 \%$ of the FPs and SPs working in $\mathrm{MoH}$ across the country was achieved $(63.4 \%$ and $34.6 \%$, respectively; $n=1624)$.

Factors such as variety of professional experience, physical conditions of health institutions, and the number of admitted patients might have an influence on the knowledge, attitude, and behaviors of the physicians in terms of RUM. ${ }^{19-21}$ Considering the age and working duration after graduation, it can be said that in both groups participants "have moderate professional experiences". Study data overall suggest that physicians in both groups do not allocate adequate time for offering an individualized therapy, tend to overprescribe and write prescriptions with large numbers of drugs, and experience some problems about informing their patients. These findings may be attributed to several reasons. For instance, FP and SPs declared that in average 52 and 48 patients per day applied them, respectively. 
Sustainable and qualified healthcare also requires the daily number of patients to whom physicians provided care be limited. In this regard, it might be considered that the numbers in this study were high, carrying some risks in terms of RUM. In accordance with the principles of RUM, it is essential that physicians allocate sufficient time for the patient's diagnosis and treatment. $^{2,3,22}$ It is obvious that this time is in close association with daily number of patients applied to the physicians. Excessive numbers of patients may negatively influence the quality of the healthcare provided to themselves, including insufficient time allocated. Increased patient volume applying to outpatient clinics in Turkey is a long-standing problem, discussed for many years with ongoing efforts towards solutions. In fact, insufficient number of physicians is an important cause. Indeed, 2009 and 2010 statistics reported that the average number of physicians per 100,000 people in the WHO-European-Region and European Union was 340 and 322, respectively, compared to that in Turkey, being even less than half of these numbers (156 physicians). ${ }^{13}$

In general, depending on factors such as the content of the offered treatment and patient characteristics, the time required for treatment arrangement is expected to take a period of about 6-10 minutes. When the time required for examination and other procedures is also added, adequate time per patient should be $>10$ minutes. According to a study conducted in six European countries, it was reported that the average consultation time of general practitioners is 10.7 minutes, ranging from 7.6 to $15.9 .^{23}$ The fact that less than $3.0 \%$ of physicians declared this time to be " $>15$ minutes" and that substantial number of physicians stated it to be " $\leq 5$ minutes" (30.6\% and $50.3 \%$, respectively) were remarkable findings suggesting lack of time issues. Accordingly, the reported durations both in other national studies and this study could be regarded as lower than expected. For instance, in a study conducted in primary healthcare centers in Izmir, the average of this time was reported as 4.1 minutes. ${ }^{24}$ In another study performed in a hospital in Istanbul, 39\% of the physicians declared this time as " $\leq 5$ minutes" and $4 \%$ of them ">15 minutes". "The lack of this time may be directly or indirectly associated with some other negative effects addressed in this study. These include, for example, the tendency of the physicians to prescribe to substantial amount of patients, even to those patients in whom they do not perform PE; their tendency to give in to the pressures from their patients in terms of drug prescription requests; their predisposition towards polypharmacy; their negligence of non-pharmacological recommendations; and failure to provide sufficient information to their patients about prescribed drugs. Furthermore, it was understood that the opinion of the physicians about "the average time required to allocate for a patient interview" and "the time they allocated in their daily routine" as mentioned above was not compatible. Considering the responses about their experiences in routine practice, it was remarkable that the percentages of FP $(32.8 \%)$ and SPs $(28.1 \%)$ stating this time as ">15 minutes" are more than expected. Though seemed as contradictory at first glance, this situation reveals that most of the physicians are aware of the insufficient time they allow for the patients during their daily practices. Indeed, critical findings stand out when the time declared to be allowed by the physicians for their patients is taken together with their opinions about whether this time is sufficient or not. For instance, it was observed that most of the FPs and SPs found this time either "insufficient" $(26.3 \%$ and $35.9 \%$, respectively) or "partially sufficient" (54\% and 48.6\%, respectively). These findings were detected to be comparable with the results of the study conducted in Istanbul, where $84 \%$ of the physicians were reported to declare this time as insufficient. ${ }^{9}$ All of these findings actually suggest that physicians experience time issues during patient interviews and that they were aware of this. This awareness can be interpreted as a sign of physicians' dissatisfactions with current situation in terms of RUM, hence being open to change. These approaches of the physicians should be properly considered whilst planning the dissemination activities regarding RUM.

Apart from leading to allocation of insufficient time to the patients, an increase of the number of patients per day may also cause other quality problems in healthcare services. For instance, the chance "to provide adequate time for drug selection" that is essential for a successful therapeutic approach may not be efficiently achieved in the settings with a heavy patient load. Within the framework of the RUM principles, physicians should carefully use "efficacy, safety, suitability, and cost" criteria while choosing drugs in a rational manner. ${ }^{1}$ In our study, insufficient time allowed for drug choosing was found to be associated with the daily volume of patients applied to the physicians. Accordingly, it appears that almost all physicians could allow enough time for drug choosing if the number of patients per day is $<20$, whereas this duration is negatively affected by an increase in daily number of patients. In this study, the approaches of the FP and SPs about RUM differ from each other in some respects. For instance, it was remarkable that the SPs examined more patients and wrote less prescriptions than the FPs. The percentage of patients examined by FPs was less than that by SPs (those declaring to "examine more than three-fourth of their patients" are $40.1 \%$ and $84.9 \%$, respectively). This finding is also supported by another study conducted in 2010 in the same places as this study, where patients declared that $72.8 \%$ of them in FHC and $89.9 \%$ of them in $\mathrm{SH}$ were examined by the physicians. ${ }^{25}$ Identification of these findings pursuant to patient and physician statements might be associated with various characteristics of patients applying primary care centers and hospitals. Indeed, in a patient survey-based study, the percentage of those not examined upon applying for "control visit and demands for prescription or resting report" in FHCs was reported to be higher than that seen in $\mathrm{SHs}^{25}$

Leading to such problems as unnecessary and inappropriate drug consumption, drug-drug interactions, facilitation of development of resistance and tolerance to various drugs, and increased treatment costs; polypharmacy is a major type of IUM that should be avoided. Indeed, NDPP is one of the INRUD 
(International Network for the Rational Use of Drugs) criteria of the WHO. An elevated value is deemed to be against RUM, which is demanded to be decreased by reducing NDPP. ${ }^{1,17}$ It was detected that FPs prescribed more drugs per prescription compared to SPs (3.27 and 3.07 drug items in average, respectively). When the NDPP was grouped by their numbers, it was encountered that no one among FPs and only a few physicians in SPs $(0.9 \%)$ has the habit of writing only one drug item per prescription. In a study conducted in Andorra, the percentage of prescriptions with one drug item was reported as $31.8 \%{ }^{19}$ A US study in 2009 reported "at least one drug item per prescription" for $68.1 \%$ of the population whose medical records were analyzed, " $\geq 2$ drug items per prescription" for $51.6 \%$ of those and " $\geq 5$ drug items per prescription" for $21.2 \%$ of the population were written. ${ }^{26}$ In a study conducted in similar health centers and provinces in 2009, the NDPPs were reported to be 2.96 and 2.75 in FHCs and SHs, respectively. ${ }^{27}$ Other studies conducted in Turkey between 1998-2005 reported these values as 2.9, 3.3, and 3.5. ${ }^{24,28,29}$ Based on both our study as well as most of the other studies in published literature, it may be suggested that FPs partly tend to write more drugs to their prescriptions than that of SPs. It may be advocated that generally the physicians in Turkey, more prominently the FPs, tend to practice polypharmacy, compared with the results of the published studies conducted in various Asian countries, reporting NDPPs between $2.08-2.91 .^{12,30-33}$

Prescription without PE is the leading unfavorable practice performed by the physicians in terms of RUM. Writing a prescription to the patient without performing the required PE, and hence skipping confirmation of the diagnosis is an unacceptable attitude regarding RUM. In our study, only $44.0 \%$ of the FPs and $64.7 \%$ of the SPs declared that "they do not write a prescription for their patients without PE" while others declared that they always or sometimes exhibited this behavior, reflecting IUM habits of the physicians in overall. This could be considered as one of the significant findings of the study, addressing the need for RUM-based interventions to correct. As in this study, the other studies conducted in Turkey also show that the tendency "to prescribe upon complaints of the patients without PE" is usually high. In a study in Istanbul, patients reported that this habit was practiced as "always" and "sometimes" by $14 \%$ and $36.6 \%$ of the physicians. $^{22}$ In a study conducted in the same city in primary care, it was reported that $58.3 \%$ of the physicians "prescribed without performing PE". ${ }^{29}$ In our study, it has been observed that the habits of the physicians about this issue showed a difference between FPs and SPs. In this regard, it is remarkable that FPs show within-group similarities while a more heterogeneous approach is shown among the SPs. Accordingly, it is understood that the tendency to exhibit this habit is more common among male SPs, those who are $>45$ years, and junior SPs.

According to the RUM principles, providing information to patients about their diseases is one of the most important responsibilities of the physician. ${ }^{1,2,4,8}$ In our study, $77.9 \%$ of the FPs and $82.6 \%$ of the SPs declared that they "always" inform the patients about their diseases, which can be considered as positive. However, this attitude is expected to be $100 \%$ independent from any conditions. Two studies conducted in Istanbul reported this attitude to be shown by $62.2 \%$ and $74.7 \%$ of the physicians. ${ }^{34,7}$ Though it has been partially improved compared to past, the expectations about this issue has not been completely met yet.

One of the impressive findings of the study is that the habit of "providing information to the patients about their diseases" varies on gender. Although no significant difference was observed in SPs, females were found to be more successful than males among FPs in this regard. Consistent with this finding, female physicians in the primary care were demonstrated to allocate more times for their patients and provide more comprehensive healthcare than their male counterparts, as reported by two different studies conducted in the United States (USA) and the Netherlands. ${ }^{21,35}$

Both FP and SP groups revealed that physicians mostly (94.4\% and $92.7 \%$, respectively) inform their patients "about their treatments", which can be regarded as favorable at first glance. However, when the details of the treatment were interrogated, it was observed that these attitudes of the physicians were below the expectations, which vary by the groups and some of the demographic characteristics within these groups. Our study showed that FPs and SPs highly declared that they "always" or "sometimes" informed their patients about the usage of the drugs prescribed. It was identified that these responses had similarities with a previous study. ${ }^{34}$ As reported by a patient survey across Turkey in 2010, patients declared that the physicians in FHCs and SHs informed vast majority of their patients about drugs per se $(89.1 \%$ and $87.8 \%$, respectively) while the remaining were only informed if they would have asked $(10.9 \%$ in FHCs and $12.2 \%$ in SHs). ${ }^{25}$ In other respects, it is noteworthy that the habit of "giving patients information about drugs" differed by some characteristics of the physicians in our study. In both FPs and SPs, this habit was observed to be practiced successfully by females and youngers, compared to males and older ones, respectively. This pointed out the differences required to be considered in RUM improvement activities applicable for physicians.

Regardless of whether offered treatments consist of drugs or not, non-pharmacological therapy should be recommended almost in every disease, including many life style modifications, practices, etc. It is essential that physicians make a clear explanation concerning these instructions to their patients. ${ }^{1,2,4,8}$ Our study pointed out that the number of the physicians providing this information was less than expected $(50.4 \%$ of the FPs and $56.1 \%$ of the SPs). Earlier studies in Turkey reported this information to be provided between 18.8 $62.6 \% .^{7,9,22,34}$ When our results were compared with those published in the literature, it is figured out that although partially improved, incompetence of the physicians substantially continues. Furthermore, it is remarkable that males and SPs were much more inadequate compared to females and FPs, respectively. 
Information such as dosage, administration way, duration of treatment, etc. should "always" be thoroughly explained to the patients by their physicians managing the treatment. It is non-excusable that this information could be imperfectly given to the patients by some justifications arguing that they can be obtained "from the pharmacist or by reading the prescription". Such negative approaches are among the major problems of the IUM, causing many potential health problems and economic losses. . $^{26,29,36}$ When the frequency of the kind of information about drugs "always" provided to the patients by FPs and SPs in this study was analyzed, it was observed that these expectations remain well behind in both groups. Among these types of treatment-related information, FP and SPs mostly preferred to provide information about "dosage", "duration of treatment", and "administration way". A patient interview study identified similar frequencies, where patients were reported to be most frequently informed about "the dosage" and "duration of treatment". ${ }^{25}$ Consistent with those in the literature, this finding suggests that physicians' statements overlap that of patients, implying these attitudes of the physicians to reflect on their behaviors. A study conducted in the USA reported that at the time of discharge, $80 \%$ of the patients received instructions about their medications and $76 \%$ of them got information about their diseases. ${ }^{37}$ The effectiveness or ineffectiveness of prescribed drugs are directly related to adopting good practices. A physician is expected to confine this information not to some subheadings, yet to extend it covering all the aspects of the drug: the name, duration of use, therapeutic effects, possible adverse effects, etc. Incompetency of an informative approach in this manner might also be associated with other before-mentioned, unfavorable attitudes of the physicians. Moreover, it is closely associated with reasons such as excess workload of the physicians due to extreme numbers of patients, insufficient time for patient care, demands for prescriptions, etc. On the other hand, delivery of this performance at an expected level requires the physician to have sufficient knowledge of pharmacology, where diverse problems worldwide were shown to exist. Problem-based rational pharmacotherapy trainings which has become gradually widespread and recommended by WHO contribute to the solution of the problem. ${ }^{1,2,5,6,38}$ In this respect, Turkey has made progress in last decade. ${ }^{8,29,39}$ The results of our study suggests the necessity of these trainings provided to physicians and physician candidates to be further disseminated.

Patients may demand for prescriptions of the drugs that they are using or they are going to use due to various reasons. This may lead to serious IUM problems in case the physician loses command over it. In this study, physicians in FP and SP groups declared that patients "most frequently or frequently" applied them to demand for prescriptions of "analgesics/antirheumatics", "cold drugs", and "antibiotics". Analgesics and cold drugs are among the frequently preferred drugs by the patients for "self-medication". In fact, such irrational use of these drugs is common. A German study of over-the-counter (OTC) self-medication usage in children and adolescents between 2003-2006 reported that $32.1 \%$ of the detected drugs were associated with respiratory system and that there were major problems concerning inappropriate use. ${ }^{40}$ In a study conducted in Australia between 2006-2007, it was reported that parents often made their children use OTC medications, and that over $40 \%$ of the parents made them use those cough and cold drugs with efficacy issues and safety risks. ${ }^{41}$ Overuse of the antibiotics in Turkey has reached very critical levels, far above the world average. ${ }^{15}$ In order to solve this problem, the health authority addressed this issue as the top priority in RUM spreading program. ${ }^{42}$ The fact that antibiotics were also among the drugs often tried to be demanded by the patients for prescriptions in our study, is an important detection disclosing the irrational antibiotic usage problem in this manner. This reveals the need for public awareness activities in terms of RUM, particularly for specific leading drug groups.

During planning of a treatment with respect to the RUM principles, physicians should make sure that provided information is properly understood by the patients. Therefore, after explaining the use of the drugs to their patients, physicians should have their patients to repeat these instructions so as to ensure that whole information is properly and sufficiently understood and fill any possible gaps in their mind. ${ }^{2,9,29}$ In a modelling study testing the comprehensibleness of the given medical information to the patients, it was reported that "the model positioning the patients at the center and facilitating a collaboration by making them to repeat what they told" would be thought to be better understood by the patients, and consequently preferred more than its alternative options. ${ }^{43}$ Another study in the USA reported that the opportunity to confirm that the provided information was understood was offered to only $22 \%$ of the patients. ${ }^{37}$ As in most of the other studies in the literature, it is also understood in this study that most of the FPs and SPs do not adopt "this repeating process which make great contributions to the comprehensibleness" much. In three different studies, few physicians were reported to practice this behavior $(8.8$ to $11.6 \%){ }^{7,9,34}$ After writing a prescription for the patients, it is a rational approach to listen to how much they have understood, and to repeat missed or misunderstood parts of provided information again. This repeating behavior, which is critical for both the implementation of RUM and identification of the position of the patient about performing what is instructed, was found to be inadequate as other previously published studies, remarking continuance of these shortcomings and the need for their obviation.

Our study has some limitations. Collection of data only during May, excluding other time periods, has ignored probable diversities of answers due to seasonal differences, which may affect some of the answers in the survey. For instance, the experiences of the physicians regarding frequency of patient demands for prescriptions of cold drugs and antibiotics (as they might be easily reminded) may be influenced from seasonal factors. This possibility might be listed among the limitations of the study. Despite having a weak possibility, some other unquestioned characteristics of the FP and SPs might influence their responses. Beside, specific questions 
related to their expertise in terms of RUM was not asked in the survey applied to the SPs. These were not included to the study to exempt it from too much detailed information and to avoid the risk of reduction of physicians' responsiveness by asking excessive numbers of questions, which may be regarded as another limitation of the study.

\section{CONCLUSION}

In conclusion, with a high participation considered to represent Turkey in general, our study analyzed approaches of the physicians towards planning of the treatment and introduced the perspectives of the physicians about these issues in terms of RUM in detail. When the overall data of the study are considered, it is noteworthy that physicians in both groups did not allocate adequate time for planning the treatment, tended to overprescribe and write too many drugs on prescriptions, and experienced several problems in providing their patients with sufficient information. It could be observed that the approaches of the physicians about treatment process might be influenced by some of their demographic characteristics and by being either a FP or a SP. In particular, although more marked among

\section{REFERENCES}

1. World Health Organization. Promoting rational use of medicines: Core components, policy perspectives on medicines. Geneva: World Health Organization, 2002, 1-6.

2. De Vries TP, Henning RH, Hogerzeil HV, Fresle DA. Guide to good prescribing. A practical manual. Geneva: WHO/DAP/94.11. World Health Organization. Action Programme on Essential Drugs, 1994, 6-75.

3. Akici A, Oktay S. Rational pharmacotherapy and pharmacovigilance. Curr Drug Saf 2007; 2(1):65-69.

4. Tsiantou V, Moschandreas J, Bertsias A et al. General practitioners' intention to prescribe and prescribing patterns in selected European settings: The OTCSOCIOMED project. Health Policy 2015; 119(9):1265-1274.

5. Le Doare K, Barker CI, Irwin A, Sharland M. Improving antibiotic prescribing for children in the resource-poor setting. Br J Clin Pharmacol 2015; 79(3):446-455.

6. Laing R, Hogerzeil H, Ross-Degnan D. Ten recommendations to improve use of medicines in developing countries. Health Policy Plan 2001, 16(1), 13-20.

7. Akici A, Kalaca S, Ugurlu MU, Oktay S. Prescribing habits of general practitioners in the treatment of childhood respiratorytract infections. Eur J Clin Pharmacol 2004; 60(3):211-216.

8. Akici A, Kalaca S, Goren MZ et al. Comparison of rational pharmacotherapy decision-making competence of general practitioners with intern doctors. Eur J Clin Pharmacol 2004; 60(2):75-82.

9. Basaran NF, Akici A. Aspects of physicians' attitudes towards the rational use of drugs at a training and research hospital: a survey study. Eur J Clin Pharmacol 2013; 69(8):1581-1587.

10. Leblebicioglu H, Canbaz S, Peksen Y, Gunaydin M. Physicians' antibiotic prescribing habits for upper respiratory tract infections in Turkey. J Chemother 2002; 14(2):181-184.

11. Jain S, Upadhyaya P, Goyal J et al. A systematic review of prescription pattern monitoring studies and their effectiveness in promoting rational use of medicines. Perspect Clin Res 2015; $6(2): 86-90$.

12. Neyaz Y, Qureshi NA, Khoja T et al. Physicians medication prescribing in primary care in Riyadh City, Saudi Arabia. Literature review, part 1: variations in drug prescribing. East Mediterr Health $J$ 2011; 17(2):126-131.

13. Akdağ R. Turkey Health Transformation Program Evaluation Report (2003-2010). Ankara: Republic of Turkey Ministry of
FPs, female physicians are more likely to inform their patients about their disease, the drugs they prescribed, and non-pharmacological treatment. It would be useful to prioritize these findings during RUM dissemination activities that will be implemented both in Turkey and in other countries.

\section{Funding}

The research for this article was financially supported by the Turkish $\mathrm{MoH}$.

\section{Conflict of interest}

The authors have no conflicts of interest to declare.

\section{Acknowledgements}

The authors thank Turkish MoH, RSHCP School of Public Health/General Directorate of Health Research, for their contributions in preparation of the research report which is the basis of this article and in the process of this article's publication. The assistance of H. Gursoz, H.G. Oncul, M.N. Dogukan, the Provincial Health Directors and their staff in collecting and evaluating the data for this study is also acknowledged.

Health. MoH Publ. No:839. ISBN:978-975-590-377-4, 2011:3439.

14. Atun R, Aydin S, Chakraborty S et al. Universal health coverage in Turkey: enhancement of equity. Lancet 2013; 382(9886):65-99.

15. Versporten A, Bolokhovets G, Ghazaryan L et al. Antibiotic use in eastern Europe: a cross-national database study in coordination with the WHO Regional Office for Europe. Lancet Infect Dis 2014; 14(5);381-387.

16. Le Grand A, Hogerzeil HV, Haaijer-Ruskamp FM. Intervention research in rational use of drugs: a review. Health Policy Plan 1999; 14(2):89-102.

17. World Health Organization. How to Investigate Drug Use in Health Facilities: Selected Drug Use Indicators. Geneva: World Health Organization. WHO/DAP/93.1, 1993, 12-24.

18. Mollahaliloğlu S, Başara Bora B, Eryılmaz Z. The Ministry of Health of Turkey Health Statistics Yearbook 2010. Ankara: Republic of Turkey, Ministry of Health, Refik Saydam Hygiene Center Presidency, School of Public Health. 2011. ISBN: 978975-590-366-8, 77.

19. Vallano A, Montane E, Arnau JM et al. Medical specialty and pattern of medicines prescription. Eur J Clin Pharmacol 2004; 60(10):725-730.

20. Hajjaj FM, Salek MS, Basra MK, Finlay AY. Non-clinical influences on clinical decision-making: a major challenge to evidence-based practice. J R Soc Med 2010; 103(5):178-187.

21. Franks P, Bertakis KD. Physician gender, patient gender, and primary care. $J$ Womens Health 2003; 12:73-80.

22. Basaran NF, Akici A. Patients' experience and perspectives on the rational use of drugs in Turkey: a survey study. Patient Prefer Adherence 2012; 6:719-724.

23. Deveugele M, Derese A, Van den Brink-Muinen A, Bensing J, De Maeseneer J. Consultation length in general practice: cross sectional study in six European countries. BMJ 2002; 325(7362):472.

24. Arslan LS, Semin S. Attitudes and practices of primary healthcare center patients about drug use in Turkey. Patient Educ Couns 2006; 62(2):250-259.

25. Akıc1 A. General principle of rational use of medicine and current situation in Turkey. Turkiye Klinikleri J PharmacolSpecial Topics 2015; 3(1):1-10. 
26. Zhong W, Maradit-Kremers H, St Sauver JL et al. Age and sex patterns of drug prescribing in a defined American population. Mayo Clin Proc 2013; 88(7):697-707.

27. Mollahaliloglu S, Alkan A, Donertas B, Ozgulcu S, Akici A. Prescribing practices of physicians at different health care institutions. Eurasian J Med 2013; 45(2):92-98.

28. Akici A. Prescribing in elderly according to the principles of rational drug use and the dimentions of drug utilization in elderly in Turkey. Turkish J Geriatrics 2006; 9:19-27.

29. Akici A, Kalaca S, Ugurlu MU et al. Impact of a short postgraduate course in rational pharmacotherapy for general practitioners. Br J Clin Pharmacol 2004; 57(3):310-321.

30. Dong L, Yan H, Wang D. Drug prescribing indicators in village health clinics across 10 provinces of Western China. Fam Pract 2011; 28(1):63-67.

31. Mahmood A, Elnour AA, Ali AAA, Hassan NA, Shehab A, Srikanth A. Evaluation of rational use of medicines (RUM) in four government hospitals in UAE. Saudi Pharmaceutical Journal. 2016; 24(2):189-96.

32. Pavin M, Nurgozhin T, Hafner G, Yusufy F, Laing R. Prescribing practices of rural primary health care physicians in Uzbekistan. Trop Med Int Health 2003; 8(2):182-190.

33. Alam K, Mishra P, Prabhu M et al. A study on rational drug prescribing and dispensing in outpatients in a tertiary care teaching hospital of Western Nepal. Kathmandu Univ Med J 2006; 4(4):436-443.

34. Akıcı A, Uğurlu MÜ, Gönül N. The evaluation of general practitioners' knowledge and attitudes regarding rational use of drug. Sürekli Tıp Eğitimi Dergisi (STED) 2002; 11:253-256.
35. Bensing JM, Brink-Muinen A, Bakker DH. Gender differences in practice style: a Dutch study of general practitioners. Med Care 1993; 31:219-229.

36. Akici A, Kalaca S, Ugurlu MU et al. Patient knowledge about drugs prescribed at primary healthcare facilities. Pharmacoepidemiol Drug Saf 2004; 13(12):871-876.

37. Vashi A, Rhodes KV. "Sign right here and you're good to go": a content analysis of audiotaped emergency department discharge instructions. Ann Emerg Med 2011; 57(4):315-22.

38. Hogerzeil HV. Promoting rational prescribing: an international perspective. Br J Clin Pharmacol 1995; 39(1):1-6.

39. Akici A, Mollahaliloglu S, Ozgulcu S, Donertas B, Alkan A. Assessment of health care service in terms of rational use of medicines delivered to patients in primary health care centres and public hospitals. Turkish Family Physician 2015; 6(1):1-10.

40. Du Y, Knopf H. Self-medication among children and adolescents in Germany: results of the National Health Survey for Children and Adolescents (KiGGS). Br J Clin Pharmacol 2009; 68(4):599-608.

41. Trajanovska M, Manias E, Cranswick N, Johnston L. Use of over-the-counter medicines for young children in Australia. $J$ Paediatr Child Health 2010; 46(1-2):5-9.

42. Aksoy M, Alkan A, Isli F. Rational drug use promotional activities of Ministry of Health. Turkiye Klinikleri J Pharmacol Special Topics 2015; 3(1):19-26.

43. Kemp EC, Floyd MR, McCord-Duncan E, Lang F. Patients prefer the method of "tell back-collaborative inquiry" to assess understanding of medical information. J Am Board Fam Med 2008; 21(1):24-30. 